\title{
ESCOLAS TRAÇADAS COM RÉGUA E COMPASSO NA COLÔMBIA E NO BRASIL
}

\author{
Carlos Jilmar Diaz Soler \\ Vera Lucia Sabongi De Rossi*
}

\begin{abstract}
Tenho-me dedicado a educar a razão (...) esta é a única faculdade para a qual se deve apelar a educação. A imaginação ociosa é coisa nociva para todos, mas em cérebros traçados desde o berço com réguas e esquadros, é curioso e incompreensível. (Gragrind, 1854)
\end{abstract}

\begin{abstract}
RESUMO: Com este artigo, que é parte de uma pesquisa mais ampla, pretendemos refletir sobre o processo de escolarização da infância, em duas revistas destinadas à formação de professores para o magistério. Ambas produzidas por grupos articulados a políticas educacionais e divulgadas para as redes públicas de ensino de São Paulo (Brasil) e outra para Bogotá (Colômbia), de 1932 a 1939. Fizemos duas perguntas às revistas: $\mathrm{O}$ que podem nos dizer sobre as finalidades políticas da formação de professores para o magistério? E sobre as relaçóes entre os métodos científicos da psicologia e da pedagogia? No final, apresentamos nossas suspeitas de cumplicidade entre projetos pedagógicos e projetos políticos autoritários, atuando no conjunto das forças cognitivas, psicológicas, culturais e institucionais.
\end{abstract}

Palavras-chave: Escolarização pública. Formação docente. Psicologia. Projetos pedagógicos e políticos.

* Doutor em Educação e professor da Facultad de Ciencias y Educación da Universidad Distrital Francisco Jose de Caldas (Bogotá, Colômbia).E-mail: cjdiaz@etb.net.co

** Doutora em Educação e professora da Faculdade de Educação da Universidade Estadual de Campinas (UnICAMP). E-mail: derossi@unicamp.br 


\title{
SCHOOLS DRAWN WITH A RULER AND A COMPASS IN COLOMBIA AND BRAZIL
}

\begin{abstract}
This paper, which is part of a broader research, reflects on the schooling process during childhood, based on two journals intended to teachers' education. Written by groups articulated to educational policies, both circulated on public teaching networks in São Paulo (Brazil) and Bogotá (Colombia), between 1932 and 1939. The two questions that underpin this text are: what are the political purposes of training teachers to professorship? What is the relation between the scientific methods used in Psychology and Pedagogy? Finally, it advances the hypothesis of a possible relation between pedagogical and authoritarian political projects acting in the set of cognitive, psychological, cultural and institutional forces.
\end{abstract}

Key words: Public schooling. Teachers' education. Psychology. Political and pedagogical projects.

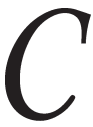

om as palavras da epígrafe, o professor Gragrind explicava que a escola da eficiência prática deveria nortear a relação dos homens consigo mesmos e com os outros, para purificar os homens do gosto, dos sentimentos e das fantasias, ainda presentes. Assim, em 1854, Charles Dickens criticou a utopia utilitarista da educação e desafiou a luta surda entre a razão e o afeto, numa cidade industrial de Lancashire, para onde crianças de cinco e seis anos eram levadas ao trabalho da fábrica, para salválas do perigo da ociosidade, porque geraria hesitação e perturbação para o racional trabalho produtivo.

Tomamos a matéria ficcional como pretexto para problematizar a natureza da educação fundada na razão instrumental, em especial da moderna psicologia escolar (medição, seleção, atitudes, inteligência), que parece viva entre nós, desde os tempos em que se tentou cercear sentimentos, afetos e fantasias. Pretendemos refletir sobre o processo de escolarização da infância, em duas revistas destinadas à formação de professores para o magistério. Ambas intituladas Educação, produzidas e divulgadas para as redes públicas de ensino de São Paulo (Brasil) e outra para Bogotá (Colômbia), de 1932 a $1939 .{ }^{1}$ Neste período, foram mantidas sob a direção o Departamento de Educação do Estado, editadas com recursos públicos e impulsionadas por grupos de intelectuais articulados em torno de ideais transformadores (da pedagogia e da psicologia) e de políticas educacionais, como instrumentos de disputa pelo exercício administrativo e 
de difusão de suas obras. Tais revistas foram distribuídas gratuitamente com a intenção de produzir saberes, práticas e representaçôes destinadas à ação pedagógica dos professores, sintonizando-os ao horizonte cultural civilizatório.

O campo investigativo das revistas destinadas ao magistério está se ampliando e demonstra que o fenômeno escritural é também estrutural no Ocidente moderno, pois está presente em diversas pesquisas no Brasil - entre elas, as de Vilela, Silva, Pinheiro e Barreira (2004), e o trabalho que reuniu os estudos sobre a revista Educação, de Cunha (2007) - e também na Colômbia - entre eles, Herrera (1999) e Diaz (2005). Essas pesquisas se ampliam também em outros tempos e espaços, tais como: na França, os estudos coordenados por Pierre Caspard (Catani \& Bastos, 1977); em Portugal, por Nóvoa (1997), que produziu um repertório analítico dos impressos de Educação e ensino nos séculos XIX e XX.

Estas revistas materializam um mecanismo de ação estratégico que, mediante a organização dos documentos escritos, considerados "científicos", disputa o controle simbólico sobre a infância e a pedagogia, difundindo ideais de sujeito e de sociedade, contribuindo para dar forma a projetos políticos. As revistas foram também um dispositivo modelizador de difusão da formação de professores, onde é possível identificar lugares de poder. Com sua leitura, os políticos-pedagogos envolvidos pretendiam orientar a prática dos professores, que eram os principais destinatários dos editores (Carvalho, 2008).

Mesmo correndo o risco de tornar autores e textos distanciados de seu próprio tempo e de minimizar importantes singularidades de cada país, mantemos nossas suspeitas que muitas ideias viajam soltas, sem fronteiras territoriais, e produzem outras ideias de efeitos inesperados. Atuam no conjunto geral das forças cognitivas, retóricas, psicológicas, sociais e institucionais, energizando-as também, de jeitos inesperados. Perguntamos às revistas: o que podem nos dizer sobre as finalidades políticas da formação de professores? Sobre as relações entre as ciências da infância, a pedagogia e a moderna psicologia?

As revistas Educação: difusão de fins educativos para formação de professores

No Brasil, a coalizão de forças que tomou o poder em 1930 perdurou até 1945, graças a golpes de poder que incluíram censura às 
manifestações culturais e periodísticas. Sob a chefia do presidente Getulio Vargas, em 1937 foi decretado o Estado Novo - ditadura totalitária, reformista e modernizadora - e as liberdades políticas e sociais foram suspensas (Hilsdorf, Warde \& Carvalho, 2004; Pandolfi, 2003). A Colômbia não conheceu o período ditatorial, mas passou por prolongados períodos de hegemonia partidária. Desde 1930 até 1945, o partido liberal assumiu o poder, depois de um período de hegemonia conservadora, iniciado em 1886 (Melo, 1986 e 1989; Palácio, 1995). Mesmo considerando as diferenças políticas, cada país, à sua maneira, tinha forte influência da Igreja católica, baixa taxa de escolaridade da população e muita esperança e muita ilusão postas na educação, como alerta Schwartzman et al. (1984, p. 51): "O que dava à educação naqueles tempos a relevância política que ela já não mantém era a crença, por quase todos compartilhada, em seu poder de moldar a sociedade a partir de formação das mentes e da abertura de novos espaços de mobilidade social e participação".

Em 15 de abril de 1932, Agustín Nieto Cabalero, inspetor geral da Educação Nacional, anunciou a abertura da Facultad Nacional de Educación ${ }^{2}$ pelo decreto expedido pelo então presidente Enrique Olaya Herrera, pela qual o Estado definiria "cual es su concepto y cuales son las normas que estima aconsejables, lo mismo en la escuela primária que en la complementaria y aquellas de segunda ensenanza que preparan de manera uniforme para todas las Carreras". Com este comunicado, é enunciada uma nova política educativa, para estabelecer conhecimentos para o magistério sintonizados com o horizonte da modernização, da profissionalização, da instrução e dos saberes e práticas educativas nas escolas.

Em Bogotá, agosto de 1933, neste marco de tensões políticas colombianas, foi a revista Educación, órgão de difusão cultural, que se tornou a voz oficial da educação. Seu diretor, Rafael Jimenez, logo no volume I (1933, p. 4), estabelece seus objetivos:

Servir a los intereses intelectuales y materiales Del magistério, que busca organizar como entidade respetable, para tomar la injerência que le corresponde en orientación e pensamiento colombiano y em la preparación de los destinos de la pátria. El objeto de la revista es contribuir al desarollo de la educación em Colómbia, servir e tribuna a los propagadores e las nuevas ideas pedagógicas y facilitar el flujo de información 
sobre las experiencias que estaban en curso, obrando como mediador entre el Ministerio de Educación y los maestros.

A revista surgiu em 1931 e tornou-se regular de 1933 a 1935. Nos seus 29 números apareceram contribuiçôes de intelectuais vinculados ao Ministério de Educação, à Faculdade de Educação, e professores estrangeiros. Para os idealizadores havia três objetivos principais: contribuir com o desenvolvimento da educação na Colômbia, servir de tribuna aos propagadores das novas ideias pedagógicas e facilitar o fluxo de informação sobre as experiências em curso, sendo mediadora entre o Ministério de Educação e os professores (Diaz, 2010).

A revista Educação, órgão oficial a Diretoria Geral da Instrução Pública de São Paulo e da Sociedade de Educação de São Paulo, começou a ser publicada em 1927, substituindo a Revista Escolar. Foi editada de 1927 a 1939, depois passou por alterações de nome, sofreu interrupções e foi até 1961, com 34 anos de existência (Vilela, 2004). Foi dividida em várias seções, com artigos de vários autores, bibliografias, informações sobre a infância, pedagogia, psicologia, educação rural, higiene, medição de inteligência, alfabetização, crônicas universitárias, entre outros.

Em janeiro de 1932, em São Paulo, Fernando de Azevedo³ redigiu, junto com mais 23 educadores profissionais, um artigo titulado "A reconstrução educacional no Brasil. Ao povo e ao governo", que circulou no primeiro volume da revista Educação. Conhecido também como "Manifesto dos pioneiros", este documento-monumento contém, entre outras, ideias da Associação Brasileira de Educação (ABE); diretrizes políticas e pedagógicas que inauguram uma nova época da revista; o rumo que buscará imprimir a Direção Geral de Educação e a orientação ideológica dos membros da Sociedade da Educação de São Paulo. ${ }^{4}$ Vamos dar a palavra ao redator Azevedo, manifestando a grande esperança posta na educação e a crítica aos 43 anos de regime republicano do país:

Na hierarquia dos problemas nacionais, nenhum sobreleva em importância e gravidade ao da educação (...). No entanto, se depois de 43 anos de regime republicano, se der um balanço ao estado atual da educação pública, no Brasil, se verificará que, dissociadas sempre as reformas econômicas e educacionais, que era indispensável entrelaçar e encadear, dirigindo-as no mesmo sentido, todos os nossos esforços, sem unidade de plano e sem espírito de continuidade, não lograram ainda crear um 
systema de organização escolar, a altura das necessidades modernas e das necessidades do paiz. Tudo fragmentário e desarticulado (...).

Em seguida, Azevedo apresenta a ameaça caótica e perigosa da inorganização do aparelho escolar e deixa-nos entrever, no projeto pedagógico e político da reconstrução educacional e cultural, o lugar especial das novas ciências experimentais para a resolução de problemas:

Onde se tem de procurar a causa principal desse estado antes de inorganização do que de desorganização do aparelho escolar, é na falta, em quase todos os planos e iniciativas, da determinação dos fins de educação (aspectos philosophicos e social) e da aplicação (aspectos technicos) dos métodos científicos aos problemas de educação. $\mathrm{Ou}$, em poucas palavras, na falta de espírito philosophico e scientifico, na resolução dos problemas da administração escolar. Esse empirismo grosseiro, que tem presidido ao estudo dos problemas pedagógicos, postos e discutidos numa atmosphera de horizontes estreitos, tem as suas origens na ausência total de uma cultura universitária e na formação meramente literária de nossa cultura. Nunca chegamos a possuir uma "cultura própria", nem mesmo uma "cultura geral" que nos convencesse da "existência de um problema sobre objetivos e fins da educação (...)”.

\section{Continua Azevedo:}

(...) se tem um espírito scientifico empregará methodos communs a todo gênero de investigação scientifica, podendo recorrer a technicas mais ou menos elaboradas e dominar a situação, realizando experiências e medindo os resultados de toda e qualquer modificação nos processos e nas technicas, que se desenvolveram sob os impulsos dos trabalhos scientificos, na administração dos serviços escolares. (Educação, 1932, v. I, p. 8)

As carências apontadas em relação aos fins da educação balizados pelos métodos científicos, bem como a ausência de uma cultura própria nos parecem indícios de um pensamento autoritário, que ultrapassa o âmbito escolar. Mesmo porque nenhuma corrente política defendeu, na historia brasileira, a constituição de uma sociedade culturalmente pluralista, que desse a cada nacionalidade aqui aportada e aos próprios habitantes primitivos do país as condiçóes de manter e desenvolver sua identidade ética e cultural. Se, por um lado, os pensamentos de Oliveira Viana e de Francisco Campos podem ser considerados expressivos do ideário político daquele período, não é difícil imaginar a permanência 
secular de grupos que conservam vivos os laços de nacionalidade pelo estreitamento de suas tradições culturais (Swartzman et al., 1984).

Tal projeto tornou-se visível também com as transcrições das teses apresentadas nas Conferências Nacionais de Educação e de artigos publicados nas comemoraçôes das Semanas de Educação, de 1927 a 1930. Os temas escolhidos eram representativos de projetos civilizatórios que pretendiam romper com o atraso social do Brasil de então, introduzindo na modernidade os estratos populacionais menos cultivados (no entender dos proponentes). Tais projetos divulgavam ideias como as de higienizar, regenerar a população pela educação, reordenar espaços e tempos, conquistar o progresso dentro da ordem (Vilela et al., 2004).

O manifesto que circulou na revista foi dirigido ao povo brasileiro e ao governo, por educadores que assumiram compromisso com o debate público sobre a reconstrução nacional, atribuindo à escola pública o papel democratizador do acesso à educação. Este manifesto se converteu em uma proposta de intervenção das elites e radicalizou o cenário político do período, já que os pioneiros propunham uma intervenção racional no sistema educacional e uma educação científica do espírito. Por outro lado, os intelectuais ligados à hierarquia católica condenaram, duramente, o conteúdo do manifesto e a seus responsáveis (Xavier, 2004).

O professor deveria possuir conhecimentos dos homens e da sociedade para perceber, além do aparente e do efêmero, o jogo poderoso das grandes leis científicas que dominam a evolução social, e a função da escola na diversidade das forças sociais que cooperam na obra política, de cunho organicista, da civilização. Essa aliança entre políticas e ciências pode revelar o substrato temporal da mudança envolto na obra de falsos extremos (antigo $x$ moderno, novo $x$ velho), uma vez que era preciso formar novos professores para a nova escola, com novas práticas e novas concepções de infância.

Ilusões similares encontramos em Bogotá. Em 1935, Agustín Nieto Caballero, ${ }^{5}$ director nacional de Educación Primaria y Normalista, inspetor geral da Educação Nacional, na tentativa de organizar o aparelho escolar, assim apresentou, na revista Educación, a necessidade de vínculos com modelos europeus, com profesores estrangeros: 
Profesores prestigiosos fueron llamados del extranjero para que vinieran a colaborar con nosotros, especialmente en el sector de la psicología aplicada a la educación, al mismo tiempo que creábamos becas de estudio fuera del país para los más distinguidos alumnos de los Cursos de Información. Ligada la Inspección Nacional desde el comienzo de su gestión a importantes centros científicos del exterior, muy particularmente a la Oficina Internacional de Educación de Ginebra, a la que adhirió el gobierno de Colombia desde comienzos de 1932, encontramos halagadores facilidades para el feliz desarrollo de nuestros propósitos. (Educación, 1935, n. IV, p. 24-25)

Em seguida é possível entrever, circulando pelas revistas de Bogotá, um projeto de construção de imagens de regeneração e de ordem, em defesa do tesoro universal, ou seja, da ciência universal, que já fora inventada (!) por especialistas "para hacer de nuestro pueblo la fuerza sana y armoniosa”, os colombianos integrais. Vamos ouvir Caballero (op. cit., p. 3):

Todavía, gentes bien intencionadas gastan sus energías en buscar como un tesoro perdido lo que llaman autóctono. "Nada de extranjerismo", dicen. "Hagamos nuestra escuela indígena". "Métodos propios". "Pedagogía nacional". Algunos llegan a pedirla: "Departamental". ¿'Tiene esto sentido? ¿No son acaso la ciencia y la cultura un tesoro universal? Las naciones todas se inspiran hoy unas de otras en sus realizaciones educativas. La ciencia es una misma en todas las latitudes y ella es la que estructura todo lo que no es empírico. ¿Para qué inventar lo ya inventado, y porque es tan modesto que nos contentemos con el limitado acervo de enseñanzas que nos dejaran los Muíscas y Caribes?.

Seamos colombianos "integrales" como lo piden los autóctonos, y sobre todo mostremos este colombianismo en un fervor que se traduzca en hechos, pero en ningún caso aconsejemos trabajar con el hacha de piedra primitiva, sino con los instrumentos creados por esta civilización de nuestro siglo, que pertenece a la humanidad entera. Dejemos a los especialistas que interpreten los jeroglíficos chibchas, y que los traduzcan al idioma de nuestros días, pero no pongamos a un pueblo entero de cara al pasado, para que en él busque su redención. No tenemos derecho de ocultarse al indígena ni al mestizo, ni al blanco, los avances que la humanidad ha conquistado para provecho de todos. El criollismo entendido así es una injusticia monstruosa. No hagamos caricaturas de lo extranjero, pero estudiemos atentamente lo que se hace fuera, y veamos de asimilarlo en cuanto pueda servirnos para hacer de nuestro pueblo la fuerza sana, armoniosa y respetable que anhelamos construir. 
Na Colômbia, todo o período de produção e divulgação das revistas foi marcado por intensos debates sobre a educação pública e por reformas legais orientadas à formação para o magistério e para a apropriação seletiva das práticas da pedagogia ativa (inspiradas em Decroly e, depois de 1935, em Dewey), e à prioridade de vincular a educação rural do campesinato ao ideário liberal. Neste período de embates pela hegemonia política entre Igreja e Estado, havia quatro tendências de apropriação estratégica dos postulados da Escola Nova (ou escola ativa), assim denominadas: escola examinadora, centrada nos exames psicológicos e médicos dos estudantes; a escola defensiva para a redenção da raça; a da reforma dos métodos de ensino e a da educação para a democracia, que enfatizou a educação pública (Obregon \& Vahos, 2004).

No Brasil, também havia várias ideologias em confronto: os que preferiam a educação técnica sobre a humanística; os que definiam o ensino universal contra as distintas escolas para cada setor social; os defensores da escola pública e os guardiões da iniciativa privada; os que punham ênfase na educação das elites e os que davam prioridade à educação popular. Os movimentos de ideias dos projetos pedagógicos mais significativos foram: o da Escola Nova (liderado por Fernando de Azevedo, em São Paulo, e por Anísio Teixeira, no Rio de Janeiro), marcado fortemente pela orientação de Dewey e com a defesa da escola pública laica, universal e gratuita; o da Renovação Católica - que se opunha às ideias modernas perigosas (liberalismo, positivismo e comunismo) e sua crença nos poderes das ciências e da técnica (ensino de habilidades e competências); o das Forças Armadas e o Projeto Fascista de Francisco Campos, que justificaram os fundamentos políticos e ideológicos do Estado totalitário com o imperativo dos tempos modernos e com os seguintes pressupostos: falência do Estado liberal-democrático; necessidade da cultura e da mentalidade de massa com forte apelo a formas elementares da solidariedade humana e do primado da irracionalidade. Assim afirmava seu mentor, Francisco Campos: "O irracional é o instrumento da integração política total e o mito, sua expressão mais adequada, a técnica intelectual de utilização do inconsciente coletivo para o controle político da nação" (Swartzman, 1984, p. 63).

Psicologia da infância escolarizada

As relações entre ciências sociais, ciências da educação e sociedade são mais estreitas e complexas do que imaginamos. Introduzir novos fins 
para a educação, na década de 1930, teve importância maiúscula no processo de reorganização do governo dos pobres, de objetivações sobre a criança pobre, circunscrevendo tais objetivações aos destinos de cada país. As ciências sociais e a psicologia forjaram ferramentas para transcender contingências individuais e conjunturais no processo de escolarização de massas, como uma tecnologia para avaliar indivíduos, organizar didáticas de salas de aula, materiais de ensino, disciplinas escolares (Popkevitz, 2003).

Em sua forma moderna, nos dois países, tais ciências construíram seu objeto, que foi capitalizado por parte dos educadores e Estados com intençōes de ordenar a realidade e assegurar o processo de formação de novos professores para as escolas normais que, na década de 1930, já estavam em marcha em ambos os países. Como matéria a ser ensinada, a psicologia experimental foi assumida na Colômbia, em 1933 (Sáenz, Saldarriaga \& Ospina, 1996). No Brasil, em São Paulo, foi introduzida no ano de 1916, na Escola Normal "Caetano Campos" (Tavares, 1996). A organização curricular das escolas normais e a difusão de novos saberes seriam a base para atingir os novos fins propostos para a educação. Conforme Nunes (2001, p. 107):

Pode-se afirmar que os educadores profissionais, ao liderarem as reformas de instrução pública em alguns dos maiores centros urbanos do país, nos anos 20 e 30, se deparavam com uma tradição que tornara privada a ordem pública. A partir da crítica a escola existente, que se caracterizava pela seletividade social e seus destinatários, pela formação propedêutica e por conteúdos pedagógicos formalistas, enfatizavam a escola única, dirigida a todos; a compreensão do papel da instituição escolar na constituição da sociabilidade; uma pedagogia que valorizasse a individualização do educando e a consciência do ser social do homem; o caráter público da educação, entendido como sustentação financeira do Estado, apto a acolher a diversidade educacional. Essa proposta, por eles idealizada como reconstrução do sistema educacional, tratava-se de construir um novo professor para uma nova educação. (Grifos do original)

Neste período histórico, predominou nas escolas infantis de São Paulo e de Bogotá a ilusão de um futuro limpo, higienizado, isento de sentimentos. Reconhecer este marco para a infância e seus efeitos sobre as práticas pedagógicas permite-nos vislumbrar a introdução dos sistemas de conhecimento, seus códigos de percepção, seus sistemas valorativos e de produção simbólica, na realidade configurada para a mesma infância. Tal como assinala Elias (1994, p. 55): 
Lo que llamamos conocimiento es el significado social de símbolos construidos por los hombres como palabras y cifras, dotados con capacidad para proporcionar a los humanos medios de orientación. Estos, en oposición a la mayoría de las criaturas no humanas, no poseen medios innatos o, como más frecuentemente se dice, medios instintivos de orientación. Los seres humanos tienen que adquirir al crecer, mediante el aprendizaje, los conjuntos de símbolos sociales, con sus correspondientes significados y, con ello, partes del acervo social de conocimientos de sus mayores.

Nesta perspectiva, as crianças não existem como tal, existem as ideias que fazemos delas e que, em determinados contextos, podem se cristalizar em formas de razão e de produzir efeitos inexplicáveis, expressos em particularidades subjetivas. As matrizes históricas de interpretação, que colocaram os eventos em uma cronologia secular, foram se configurando, desde o século XVII, sobretudo graças ao protagonismo do discurso científico e suas promessas feitas à sociedade de fins do XIX às primeiras décadas do XX. Estruturar a compreensão da realidade nesta lógica fez com que as crianças tomassem parte de um fluxo universal de desenvolvimento humano e social (Áries, 1978). Houve forte apelo no evolutivo, nas consequências, nas etapas de desenvolvimento, diante da necessidade de ocupar espaços diferentes dos adultos e destinados a sofrer intervenções.

O processo de escolarização massiva das crianças conduziu a uma forte discussão política e pedagógica, que recorreu às "revelações" provenientes de análises, descriçóes e práticas que se configuraram desde a nascente psicologia. Na literatura científica surgiu grande número de trabalhos sobre a criança. Entre os principais autores europeus, que inspiravam fortemente as comunidades acadêmicas, do Brasil e da Colômbia, e que escreviam nas duas revistas (artigos, referências bibliográficas, traduçôes, comentários), encontravam-se Claparede ${ }^{6}$ (vinculado ao Instituto J.J. Rousseau, em Genebra), Binet, Walon e a figura fundamental do pragmatismo do século XX, o norte-americano John Dewey, que demonstrou sua fé na inteligência e nos meios instrumentais de sua realização. ${ }^{7}$

Encontramos poucos estudos, do período analisado, sobre a relação entre pedagogia e psicologia. Saenz Obregon (2003), em Las ciencias humanas y la reorientación de la pedagogía, alertou que "es necesario abordar algunos temas relativos al origen de la psicología científica y a su influencia en la renovación de las teorías pedagógicas, las prácticas escolares y la organización de las instituciones de enseñanza” (p.13-14). 
Sobre a relação entre escola, psicologia e pedagogia em São Paulo, ver Tavares (1996) e Morgotto (2000); e o estudo de Warde (2001) sobre a perspectiva da história das ciências, ou das disciplinas - a autora escreveu sobre psicologia, criança e pedagogia.

De acordo com Warde (op. cit.), foi Herbart quem propôs que se retirassem os fins da educação da psicologia, a iniciação do caminho, os meios e os obstáculos. De Herbart a Claparède, a psicologia ancorou os estudos pedagógicos e ganhou espaço também nas universidades reformadas. Conforme aponta a autora (2001, p. 323-324):

Se para Durkheim a sociologia era a arma dos republicanos para fazer valer a "moral laica e a solidariedade nacional", para Claparède era a psicologia o instrumento de luta contra uma filosofia especulativa e metafísica, bem como a luta pela inoperância e despreparo dos poderes instituídos em questões educacionais. Não é casual a identidade permanente alardeada por Claparède entre seus preceitos científicos e os da psicologia funcionalista norte-americana, destacadamente a de Dewey, a partir da qual funda sua "educação funcional". Naquela psicologia, ele identificava as mesmas armas conceituais e metodológicas para a decifração da vida mental. Como ele, Dewey e os seus parceiros pragmatistas estavam lutando contra a filosofia especulativa e metafísica.

Percebemos, através das duas revistas, que a moderna psicologia escolar contribuiu para configurar novos modos de conceber o mundo da infância, transformar linguagens, perspectivas, palavras, termos e expressões. Dentro de sistemas de espaço-tempo, dentro de uma cronologia progressiva e de uma estrutura hierárquica, os individuos mais novos no mundo, os recém-chegados, puderam ser vistos como parte de um sistema de relaçóes sociais, como crianças escolarizadas, como educandos em processo de desenvolvimento.

No processo de reorientação das práticas pedagógicas, buscou-se atingir as finalidades destas duas revistas. Seus autores questionaram a rotina dos métodos, acionaram o processo de desenvolvimento da inteligência e do caráter. Mediante a indagação histórica da objetivação do mundo infantil, desde o XIX, foram construídos cenários, práticas e saberes de experts, com um aparato cultural racionalizado que assegurou a diferença social e certa homogeneização do discurso. Contudo, este movimento de ideias também abriu caminhos para vislumbrar o que resistiu a ser capturado pelo discurso e que até hoje gera um profundo 
mal estar: deserção escolar, dificuldades para aprendizagem, falta de motivação, indisciplina, descontentamento com as escolas. ${ }^{8}$ Para Warde (2001, p. 329-330):

Autores contemporâneos (por exemplo, Nagle, 1976, e Houssauye, 1991) têm postulado que é exatamente da natureza do campo pedagógico privilegiar a utilização instrumental sobre a utilização conceitual; nele reina o primado do operacional (o como) sobre o conceitual (o porquê); a sua lógica é a do receituário, respostas às situações correntes, soluçôes pontuais aos problemas frequentes para os quais a psicologia tem negado munição.

Se a tese que emergiu na segunda metade o século XIX, segundo a qual a criança seria o termo articulador entre a psicologia e a pedagogia, não resultou em práticas mais vantajosas para a infância, o problema não deve ser procurado na lógica interna das relações entre aquelas disciplinas, mas sim na impossibilidade de ambas darem conta, porque são seu próprio espelhamento, das condições sociais para as quais a sua infância é negada.

Todavia, conforme sugere Diaz (2010), reconhecer a íntima vinculação entre os conhecimentos dos experts, dos especialistas, como exercício de poder, leva à pergunta de como pensar uma ética do conhecimento, considerado como prática política, em uma tarefa central na investigação sobre o social - a de desfamiliarizar o familiar -, o que se considera dado como conhecimento, quem pode falar e segundo quais critérios de verdade.

Mediante a análise destas revistas, percebemos que aqueles discursos geraram princípios de ação imbuídos de afetividade e de autorização. A decisão de considerar todo fato social como construído e real permite traçar um caminho que transcende as duas posições aparentemente opostas, que constituem o positivismo cientificista e o relativismo denunciatório, e permite compreender a ciência e seus modelos teóricos como construções sociais. Estas construções contribuem para configurar a sociedade e o Estado e atuam sobre a comunidade e suas lógicas de funcionamento, convertem-se em saberes prescritivos e práticas políticas de organização do trabalho.

É relevante pensar sobre a possível atualidade da relação entre a Pedagogia e a Psicologia, a partir de Herbart, em 1806:

A primeira ciência do educador, embora não a única, haveria de ser a psicologia na qual se determinam a priori todas as possibilidades das emoçóes 
humanas (...). A construção a priori do aluno é, pois, em si uma expressão falsa e, por ora, um conceito que a Pedagogia não pode admitir por mais tempo. (Herbart, apud Warde, 2001, p. 330)

\section{Suspeitas e cumplicidades}

Educadores brasileiros e colombianos fizeram uso das teorias provenientes, entre outras, da moderna psicologia escolar e investiram, por meio da escola, em um projeto autoritário, em busca dos melhores povos (brancos, cristãos, civilizados), regenerados e em harmonia social. Inspirados nos dados geográficos, biológicos e higiênicos, com diversos referenciais teóricos, assemelhavam-se na crítica às instituições liberais republicanas e construíram imagens de um povo "sem instrução", que foi diferenciado no trabalho e discriminado na sociedade (De Rossi, 2005, 2007). ${ }^{9}$

A produção de conhecimentos advindos da moderna psicologia e da pedagogia, em sua tarefa de materializar a ideia de infância nas instituiçôes escolares, produziu armadilhas conceituais e dificultou o reconhecimento da existência de um espaço humano que transcendesse a razão instrumental (criticada por Dickens). As chamadas empresas do mundo moderno, as ciências sociais e educacionais foram criadas com a intenção de prover de teorias e ferramentas metodológicas a produção de um conhecimento sistemático sobre a realidade, com algum tipo de validade empírica. Ou seja, serviriam como instrumentos políticos de intervenção, para materializar práticas e representações sobre a escola e sobre o mundo.

Entretanto, parece que este projeto político não foi exclusivo do campo educacional. Referenciados por Bresciani (2007), é possível dizer que apelos emotivos justificaram a aposta no método das ciências, na sua aplicação universal, mesmo que respeitando as peculiaridades nacionais. Tal método impôs-se como análise isenta e objetiva e obteve créditos de diversos pensadores de vários matizes, inspirados nos chamados desacertos das repúblicas com visos liberais, que encontram efetivação apenas na presença ativa dos "ideólogos” externos. Esta retórica, presente nos principais intérpretes do Brasil, ${ }^{10}$ deixa pouco espaço à imaginação, à criatividade e à iniciativa pessoal. Tudo está prescrito, previsto e orientado por um projeto político centralizado no Estado. 
No processo da pesquisa em curso, temos desconfiado de que este emaranhado de falas, que confluem para o projeto político autoritário de país e que configuraram a imagem depreciativa do brasileiro, encontra certa sintonia com a configuração da imagem do povo e o projeto político colombiano. ${ }^{11}$ Esta construção discursiva acionou um lugar comum da produção de imagens depreciadas e suscitou desconfianças em relação as nossas capacidades intelectivas e políticas de administrar nossas instituições, não apenas educacionais, tanto nos nascidos aqui, quanto nos nascidos lá, em especial, índios, negros, mulatos e o amplo leque da classe pobre. Os projetos políticos de ambos os países estudados pareciam imersos no debate internacional da neutralidade e da objetividade, na hereditariedade de traços étnicos, no poder modelador do inconsciente coletivo e na inadequação das instituições liberais.

A investigação comparada tem um importante papel a cumprir. Os enfoques metodológicos influenciam nas (des)leituras que fazemos da diversidade de experiências acumuladas ou desaparecidas na área educacional. Importante conhecer as hipóteses de historiadores da educação, atribuídas à chamada incapacidade das escolas e dos sistemas educativos latino-americanos de 1920 a 1950. Para Ossembach (1996), a escola estava dentro dos princípios liberais e positivistas e oportunizara a chegada das ideias do progressivismo norte-americano de Dewey e do movimento europeu da Escola Nova. Diferentemente, Tedesco (1996) considera que a expansão da escolarização, que se iniciou na época dos populismos, não alterou a escola chamada de tradicional e nunca atendeu às demandas da modernização. Romero (1992) aponta que há razões profundas da herança cultural para que, todo o tempo, os sistemas escolares demonstrassem escassa vocação da capacidade para vincular o conhecimento e suas aplicaçôes, relacionando-as ao trabalho produtivo. Esta hipótese pode ser lida a partir do sentido liberal herdado do legalismo, apologia do atraso feita pela via da herança cultural, ou, no sentido marxista, da impossibilidade de articular a educação ao mundo socioeconômico da produção capitalista e da herança cultural entendida como resistência cultural (Alvares Galego, 2004).

Para explicar esta chamada incapacidade e fracasso da escola latino-americana, frente às novas exigências culturais e econômicas do mundo contemporâneo, Alvares Galego (op. cit.) concluiu que não existe associação unívoca entre ensino privado, modernização pedagógica e desenvolvimento econômico. $\mathrm{O}$ fracasso se deu por sua incapacidade de 
conhecer e de articular o conhecimento próprio de seus povos e comunidades; por construir sistemas educativos com paradigmas de outras latitudes; e por desperdiçar o acúmulo cultural dos diversos grupos que resistiram à dinâmica oficial imposta pelos sistemas de educação formal. Esta riqueza cultural e pedagógica, dispersa, mestiça e de outros povos, provenientes de outras tradições, não foi reconhecida nos sistemas de educação pelas políticas educativas. Tal reconhecimento permitiria a cada país competir no processo de globalização mundial com alguma vantagem comparativa.

As revistas analisadas também contribuíram para direcionar reformas educacionais, estratégias da normalização e práticas docentes no processo de escolarização pública. As políticas dos Estados colombiano e brasileiro, desde o século $\mathrm{Xx}$, aparentemente seguem os impulsos democráticos provenientes dos movimentos sociais e educacionais, mas operam de maneira autoritária, distanciada das políticas de intervenção. Afinal, a produção e a divulgação das duas revistas deram-se no contexto do túnel das ditaduras, quando o controle de massas e a guerra total estavam sendo construídos e a humanidade parecia condenada a perder-se nos seus labirintos. Ao mesmo tempo, e apesar de tudo, foi um tempo de sonhos, realizações e de esperanças postos na educação pública, de resistências e de oposições ideológicas advindas de escolas libertárias, mesmo numa conjuntura mundial de altíssima tensão.

Um dos aspectos constituintes do projeto civilizador da modernidade residiu na tensão entre o projeto de emancipação e, de outro, de conformação, de racionalidade alienante voltada para o controle das "provas" biológicas, sociais, políticas e culturais, enquanto relações de força e de poder de determinados grupos. Entretanto, depois de meados do século XX, as pesquisas sobre inteligência artificial vislumbram uma civilização pós-natural e pós-humana. Para Gorz (2005), capital e ciência se servem mutuamente e, ainda que diferentes, têm muito em comum. Ambos se encerram nas técnicas dessubjetivantes do cálculo, contra o retorno reflexivo sobre si. Como se descobrissem a lingua na qual Deus criou o mundo, buscam emancipar- se do gênero humano.

Será que nossos esforços intelectuais, em nome do contrapoder, respondem a esses apelos emancipacionistas de operacionalidade e produtividade? Para finalizar, recorremos à lucidez de Paz (1968, p. 27): 
Mentiríamos também se disséssemos que acreditamos na fertilidade de uma sociedade fundamentada na imposição de princípios modernos. A história contemporânea invalida a crença no homem como criatura capaz de ser modificada essencialmente por estes instrumentos pedagógicos ou sociais. O homem não é apenas fruto da história e das forças que a movimentam, como se pretende agora; nem a história é o resultado apenas da vontade humana. O homem, parece-nos, não está na história: é história.

\section{Notas}

1. Arquivos consultados em Bogotá: Hemeroteca Luis López de Mesa; Biblioteca Luis Ángel Arango; Biblioteca Nacional; Archivo del Gimnasio Moderno; Biblioteca de la Universidad Pedagógica Nacional. Em São Paulo: Biblioteca da Faculdade de Educação da Universidade Estadual de Campinas (UnICAmP); Biblioteca da Faculdade de Educação da Universidade de São Paulo (USP). No Rio de Janeiro: Centro de Pesquisa e Documentação de História Contemporânea do Brasil (CPDOC).

2. Apenas em 1939, o governo federal do Brasil organizou cursos superiores destinados à formação do magistério e à preparação de quadros técnico-administrativos.

3. Professor de Latim e de Psicologia, diretor da Faculdade de Filosofia, Ciências e Letras de São Paulo (1941-1942) e membro do Conselho Universitário, desde a fundação da UsP.

4. Fundada em 1922, tinha por objetivo congregar membros do magistério com interesses comuns de educação, para realizar a modernização e a renovação das questôes pedagógicas (Bortoleto Nery, 2001).

5. Agustín Nieto Caballero (1889-1975) cursou Direito, Filosofia, Ciências da Educação, Biologia e Psicologia. Entre 1933 e 1935, foi diretor da Educação Primaria e normalista do Ministério de Educação. Entre 1938 e 1941, foi reitor da Universidad Nacional e representou a Colômbia na UNESCO e na OEA.

6. No século XIX, o processo que levou a escola do trabalho a ser compreendida como escola ativa ou escola nova compreendeu preocupaçôes com a fadiga escolar, com a anormalidade infantil e os níveis de inteligência das crianças nas escolas. Encontramos escolanovistas tais como Binet (1909 [1985]), Claparède (1910) e Wallon (1915 [2000]).

7. Para Dewey (1936, p. 57), "a fé no poder da inteligência para imaginar um futuro que seja a projeção do que se deseja no presente, e para inventar os meios instrumentais de sua realização, é a nossa salvação. É a fé que deve ser alimentada e sistematizada; decerto é uma tarefa suficientemente ampla para a nossa filosofia”. Embora Dewey suspeitasse do conceito de intelecto puro, reinterpretou o trabalho intelectual e o prático, exaltando o trabalho físico e reabilitando os instintos. Tanto o positivismo quanto o pragmatismo identificam a filosofia como cientificismo.

8. Esta dimensão ultrapassa os objetivos deste trabalho.

9. Entre eles, encontramos Ulisses Cabral (1885), Afrânio Peixoto (1933) e Anísio Teixeira (1935). Esta pesquisa vem sendo realizada em outros tempos e espaços brasileiros e latino-americanos.

Cad. Cedes, Campinas, vol. 31, n. 83, p. 35-56, jan.-abr. 2011

Disponível em <http://www.cedes.unicamp.br> 
10. Bresciani (2007) refere-se, neste ponto, a Caio Prado Junior e Darci Ribeiro, mas, no decorrer do seu estudo, há também pensadores como Oliveira Viana, G. Freyre, S.B. de Holanda e Caio Prado Junior.

11. Não encontramos na Colômbia pesquisa desta amplitude.

\section{Referências}

ARIÈS, P. História social da criança e da familia. Rio de Janeiro: Guanabara, 1978.

AZEVEDO, F. As ciências no Brasil. São Paulo: Melhoramentos, 1932.

BINET, A. Las ideas modernas sobre los niños. México, DF: Fondo de Cultura Económica, 1909 [1985].

BRESCIANI, M.S. O charme da ciência e a sedução da objetividade. São Paulo: UNESP, 2007.

CARVALHO, M.M.C. Molde nacional y forma cívica. Bragança Paulista: CDAPH-IFAN/USF, 1998.

CARVALHO, M.M.C. O impresso como estratégia de formação: Revista do Ensino de Minas Gerais (1925-1940). Belo Horizonte: Argvmentum, 2008.

CARVALHO, M.V. et. al. Estudo de periódicos: possibilidades para a história da educação brasileira. In: Menezes, M.C. (Org.). Educação, memória, história: possibilidades, leituras. Campinas: FAPESP; FAEP; UNICAMP; Mercado de Letras, 2004.

CATANI, D.B.; BASTOS, M.H.C. (Org.). Educação em revista: a imprensa periódica e a história da educação. São Paulo: Escrituras, 1997.

CLAPARÈDE, E. Psicologia del niño y pedagogía experimental. Madrid: Crítica, 1910.

CUNHA, M.V.; TOTTI, M.A. Do manifiesto dos pioneros à sociologia educacional: ciencia social e democracia na educação brasileira. In: Manifesto dos Pioneiros da Educação. Um legado educacional em debate. Rio de Janeiro: FGV-FUMEC, 2004. 
DE ROSSI, V.L.S. Projetos pedagógicos no jogo político da ilusão versus esquecimento. In: Corbalan. A. (Coord.). Enredados por la educación, la cultura y la política. Buenos Aires: Biblos, 2005.

DE ROSSI, V.L.S. Una questión de sensibilidad política: educadores, proyectos y conflitos. In: Herrera, M.C. (Ed.). Encrucijadas e indicios sobre America Latina. Bogotá: UNAM, 2007.

DEWEY, J. La escuela y el niño. Madrid; Espasa-Calpe, 1936.

DIAZ, C.J. El pueblo: de sujeto dado a sujeto politico por construir; el caso de la campana aldeana en Colombia. Bogotá: UPN, 2005.

DIAZ, C.J. La infancia escolarizada, la psicología y la pedagogía: pensar la modernidad desde los saberes académicos en la educación. In: INTERNACIONAL DE INVESTIGADORES RED EDUCACIÓN, CULTURA Y POLITICA EM AMÉRICA LATINA, 6., 2010, Puebla. Anales... Puebla: UnAm, 2010.

DICKENS, C. Tiempos difíciles. Madrid: Fólios, 1853 [1999].

EDUCACIÓN (1933-1935). Orgabo de la Facultad de Ciencias de la Educación de la Universidad Nacional. Director Fundador: Rafael Bernal Jiménez, Rector de la Facultad.

ELIAS, N. Conocimiento y poder. Madrid: Las Ediciones de la Piqueta, 1994. p. 55.

GALEGO, A.A. Los sistemas educativos en America Latina: histórias, diagnosticos y perspectivas. In: In: Zuluaga Garces, O.L.; Ossembach SAUTER, G. (Comp.). Modernizacion de los sistemas educativos Iberoamericanos siglo XX. Bogotá: Cooperativa editorial Magistério, 2004. p. 313-356.

GORZ, A. O imaterial. São Paulo: Annalume, 2005.

HERRERA, M.C. Modernización y escuela nueva en Colombia. Bogotá: UPN, 1999.

HILSDORF, M.L.S.; WARDE, M.J.; CARVALHO, M.M.C. Apontamentos sobre a história da escola e do sistema escolar no Brasil. In: Zuluaga Garces, O.L.; Ossembach Sauter, G. Génesis y desarrollo de 
los sistemas educativos iberoamericanos siglo XIX. Bogotá: ColcienciasUniversidad de Antioquía, 2004. t.1.

MARCO, P. Entre la legitimidad y la violencia, Colombia 1875-1994. Bogotá: Norma, 1995.

NERY, A.C.B. Embates no campo educacional: a sociedade de educação de São Paulo (1922-1931). Trabalho apresentado na Reunião Anual da ANPEd. Caxambú, 2001.

NÓVOA, A. A imprensa de educação e ensino. In: CaTani, D.B.; BasTos, M.H. (Org.). Educação em revista. São Paulo: Escrituras, 1997. p. 11-31.

NUNES, C. As políticas públicas de educação de Gustavo Capanema no governo Vargas. In: Bomeny, H. (Org.). Constelação Capanema: intelectuais e políticas. Rio de Janeiro: FGV; Bragança Paulista: EDUSF, 2001.

ORLANDO, M.J. La evolución económica de Colombia, 1830-1900. In: Nueva Historia de Colômbia. Bogotá: Planeta, 1989.

ORLANDO, M.J. La literatura histórica en la República. In: Historiografía colombiana, realidades y perspectivas. Colección de autores antioqueños. Medellín, 1996. v. 107.

OSSEMBACH, G. Las transformaciones del Estado y de la educación publica en America Latina en lo siglo XIX. In: MArTinez, B.; NARODOwsKI, M. (Comp.). Escuela, historia y poder. Buenos Aires: Ediciones Novedades Educativas, 1996. p 121-147.

PANDOLFI, D. Os anos 1930: as incertezas do regime. In: FERrEIRA, J.; Delgado, L. (Org.). O Brasil republicano: o tempo nacional do estatismo. Rio de Janeiro: Civilização Brasileira, 2003.

PAZ, O. Testemunhos: o labirinto da solidão e post scriptum. São Paulo: Parma, 1968.

PAZ, O. Sóror Juana Ines de la Cruz: as armadilhas da fé. São Paulo: Melhoramentos, 1998.

PINHEIRO, A.R. Escola "Caetano de Campos": escola paulista, escola vanguardeira. 2008. Tese (Doutorado em Educação) - Faculdade de Educação, Universidade Estadual de Campinas, Campinas. 
POPKEWITZ, T.; FRANKLIN, B.; PEREYRA, M. (Comp.). Historia cultural y educación: ensayos críticos sobre conocimiento y educación. Barcelona: Pomares, 2003.

QUICENO, H.; SÁENZ OBREGÓN, J.; VAHOS, A. La instrucción y la educación publica en Colombia. In: Zuluaga Garces, O.L.; Ossembach Sauter, G. (Comp.). Modernización de los sistemas educativos iberoamericanos siglo XX. Bogotá: Cooperativa, 2004. t. 2.

QUICENO, H.; SAENZ OBREGÓN, J.; VAHOS, L.A. La instrucción y la educación pública en Colombia: 1903-1997. In: ZuluagA Garces, O.L.; Ossembach Sauter, G. (Comp.). In: Modernizacion de los sistemas educativos iberoamericanos siglo XX. Bogotá: Cooperativa editorial Magistério, 2004. p. 105-170. T. I.

ROMERO, S. La distribuición social e responsabilidades y actuaciones en el desarrollo futuro de la educación en America Latina. Santiago de Chile: Organización de Estados Latinoamericanos, 1992. (mimeo.).

SÁENZ OBREGÓN, J. Las ciencias humanas y la reorientación de la pedagogía. In: Ossembach Sauter, G. (Ed.). Psicología y pedagogía en la primera mitad del siglo $X X$. Madrid: Universidad Nacional a Distancia, 2003. p. 13-42.

SAENZ, O.J.; SALDARRIAGA, O.; OSPINA, A. Mirar la infancia: pedagogia, moral y modernidad en colombia, 1903-1946. Colciencias: Ediciones Foro Nacional por Colómbia; Ediciones Uniandes; Eitorial de Antioquia, 1996. v. 3.

SCHWARTZMAN, S.; BOMENY, H.M.; COSTA, V.M.R. Tempos de Capanema. São Paulo: Paz \& Terra; EDUSP, 1984.

TAVARES, F.A.R. A ordem e a medida: escola e psicologia em São Paulo (1890-1930). 1996. Dissertação (Mestrado) - Faculdade de Educação, Universidade de São Paulo, São Paulo.

TEDESCO, J.C. Algunos aspectos de la privatización educativa en America Latina. Quito: Instituto Fronesis; UNESCO, 1996. (mimeo.).

VEIGA, A. (Comp.). Critica pros-estructuralista y educación. Barcelona: Laertes, 1997. 
VEIGA, C. Manifesto dos pioneiros de 1932: o direito biológico à educação e a invenção de uma nova hierarquia social. In: XAVIER, M.C. (Org.). Manifesto dos pioneiros da educação: um legado educacional em debate. Rio de Janeiro: FGV, 2004.

VILELA, M.V. et. al. Estudo de periódicos: possibilidades para a história da educação brasileira. In: Menezes, M.C. (Org.). Educação, memória, história. Possibilidades, leituras. São Paulo: FAPESP; FAEP; UNICAMP; Mercado de Letras, 2004. p. 401-450.

WALLON, H. La evolución psicológica de niño. Madrid: Crítica, 1915 [2000].

WARDE, M.J. Para uma história disciplinar: psicologia, criança e pedagogia. In: Freitas, M.C. (Org.). História social da infância no Brasil. São Paulo: Cortez, 2001. p. 311-332.

XAVIER, M.C. (Org.). Manifesto dos pioneiros da educação: um legado educacional em debate. Rio de Janeiro: FGV, 2004.

Recebido em agosto de 2010.

Aprovado em outubro 2010. 